\title{
Iconología mitológica de El Contrato del Dibujante, de Peter Greenaway
}

César García Álvarez

Universidad de Leóno

\begin{abstract}
RESUMEN. El presente artículo estudia las raíces mitológicas de la compleja iconografía empleada por Peter Greenaway en su película El contrato del dibujante, y muestra que puede ser leída como una alegoría mitológica de la creatividad artística, basada en los mitos de Perséfone, Hércules, la Diosa Blanca, el Rey del Año y el Greenman, como parte de la mitología céltica y griega, y en particular de acuerdo con la interpretación de éstas ofrecida por Robert Graves.

Palabras clave: iconología, mitología, cine, Peter Greenaway.

ABSTRACT. This article studies the mythological roots of the complex iconography used by Peter Greenaway in his film The Draughtsman's Contract, showing that it can be read as a mythological allegory of the artistic creativity, based on the myths of Perséfone, Hércules, the White Goddess, The King of the Year and the Greenman, as part of the celtic and greek mithology, and particulary according to their interpretation given by Robert Graves.

Key words: Iconology, mythology, cinema, Peter Greenaway.
\end{abstract}

Una de las propuestas cinematográficas más originales y renovadoras del cine de las dos últimas décadas es la constituida por la obra de Peter Greenaway. Su cine, singularmente complejo, provoca adhesiones entusiastas y rechazos viscerales en parecidas proporciones ${ }^{1}$. Uno de los procedimientos utilizados con mayor asiduidad por el director británico es la mitologización. Los personajes son en numerosas oca-

\footnotetext{
${ }^{1}$ Dos interesantes libros se han dedicado hasta el momento a la figura del director británico. La obra de Jorge GorostizA, Peter Greenaway, Cátedra, Madrid, 1995, y la de Esteve Riambau, Peter Greenaway, la ordenación del caos, Manga Films, 1999, libro que acompaña a la edición especial de El contrato del dibujante.
}

siones construcciones elaboradas a base referencias culturales obedecientes a diferentes códigos, que intensifican la sensación de irrealidad e intelectualidad características de su cine. En este artículo nos proponemos profundizar en algunas de las claves mitológicas que en nuestra opinión se encierran en El contrato del dibujante, su segundo largometraje (1982).

El contrato del dibujante seduce inevitablemente por la brillante y barroca puesta en escena. Su esplendor visual se ve reforzado por una hipnótica banda sonora, orquestación y elaboración de obras de diferentes músicos barrocos y clásicos, en espe- 
cial de Purcell y Mozart, por parte de Michael Nyman ${ }^{2}$. Esta riqueza formal corre pareja con una increíble densidad en el argumento y los diálogos, que puede provocar una sensación de oscuridad, incomprensión e incluso rechazo por parte del espectador. Para evitarla es conveniente comenzar con un resumen de su intrincado argumento.

En 1695, Mr. Neville, un pretencioso dibujante, es contratado por Mrs. Herbert, mujer del propietario de una mansión rural inglesa, quien acaba de emprender un viaje y desaparecerá enigmáticamente, para realizar seis dibujos de la mansión desde diferentes perspectivas. El contrato que firman recoge la obligación de Mrs. Herbert de mantener relaciones sexuales con Mr. Neville cuantas veces lo desee el dibujante. Cada dibujo se realiza desde un emplazamiento exacto, en cada uno de los cuales el dibujante mantiene diferentes conversaciones con algunos personajes de la mansión. Sin embargo, para desesperación del mediocre artista, algunos aspectos de cada vista aparecen cada día misteriosamente alterados. Mrs. Talmann, hija de Mrs. Herbert, contrata a su vez a Mr. Neville para la realización de otros seis dibujos, contrato que incluye igualmente favores sexuales. Tras la realización de los doce dibujos, Mrs. Herbert contrata la realización de un decimotercero, contrato que sella mediante una nueva unión con Mr. Neville, al que realiza una enigmática revelación. Esa misma noche, durante la realización del decimotercer dibujo, se producirá un fatídico desenlace.

La relación de El contrato del dibujan$t e, y$ de todo el cine de Greenaway en general, con la mitología, no es en absoluto su-

${ }^{2}$ Los préstamos literales que Nyman toma de compositores barrocos y clásicos no aparecen nunca citados explícitamente, lo que provoca que gran número de espectadores crea que son composiciones suyas lo que no son más que orquestaciones. perficial, ilustrativa ni literal. Al contrario, la dimensión mitológica afecta al corazón y la estructura misma del sentido del filme. Greenaway no ilustra mitos, sino que construye universos que tienen entre otros un nivel de significado mitológico ${ }^{3}$. Precisamente, uno de los atractivos del cine de Greenaway radica en la insólita fusión de una visión racionalista y científica de la realidad con otra simbólica, mágica e irracional. La tensión entre ambas parece no resolverse en ningún momento, y permanecen solapadas, provocando un extrañamiento profundamente estético en el espectador, quien siempre cree poder acercarse a la resolución final del sentido del filme, el cual sin embargo parece escaparse indefinidamente.

La carga simbólica de El contrato del dibujante, como de todas las películas de Greenaway, es prácticamente inagotable. Claves mitológicas, históricas, religiosas, políticas, sociales, artísticas, filosóficas, folklóricas, musicales, etcétera, se superponen y entrelazan formando un tapiz cuya complejidad desalienta y aleja a unos, y atrapa irremisiblemente a otros. En cualquier caso, las claves mitológicas de El contrato del dibujante no son en absoluto fáciles de desentrañar, porque no se ciñen a un único mito, sino que residen en una combinación y fusión profunda del sentido de varios mitos diferentes, que pasamos a detallar.

1) Perséfone. A lo largo del filme, se realizan dos alusiones explícitas al mito de Deméter y Perséfone. La primera en boca de Mrs. Talmann, quien explica parte del mito a su sobrino. La segunda, tras el contrato para la realización del decimotercer y

\footnotetext{
${ }^{3}$ En una mitologización acorde con algunas tendencias del psicoanálisis contemporáneo, como la defendida por James HILLMAN, en obras como Reimaginar la psicología o El mito del análisis, ambas publicadas en España por la editorial Siruela.
} 
fatídico dibujo, proviene de Mrs. Herbert, quien explica de un modo un tanto oscuro el sentido del mito al atribulado dibujante. Tras esta revelación mitológica, el espectador descubre que en ella reside una de las claves más profundas del significado de la película. En efecto, en la conversación final, Mrs. Herbert revela que los hombres, infértiles y temerosos de la fecundidad de la mujer, las raptan como Hades a Perséfone, y construyen jardines y palacios como en el que ella vive para paliar y compensar la infertilidad y el cautiverio. Las granadas que uno de los habitantes de la mansión ha entregado a Mr. Neville, y que éste regala a su vez a Mrs. Herbert, cobran un triple y siniestro sentido. Por un lado, revelan que Mrs. Herbert y Mrs. Talmann son Perséfone retenidas por Hades, por Plutón, dios de las riquezas, al que encarnan sus maridos, burgueses y aristócratas llenos de ambición y avaricia. Pero como quien las come es el dibujante, será él quien quedará retenido para siempre en el Hades, lo que ocurrirá esa misma noche. Por último, el jugo de la granada, que puede entenderse como sangre, se convierte en señal de acusación del asesinato de Mr. Herbert por el dibujante, y prefigura el propio sacrificio de éste último, gracias al cual alcanzará, paradójicamente, la inmortalidad, simbolizada igualmente por la granada. Las dos respetables damas inglesas son, por tanto, Perséfone, o Deméter y Perséfone, si se prefiere.

2) Hércules. El paralelo entre el dibujante y Hércules es más profundo de lo que parece a primera vista. Los doce dibujos encargados se corresponden con los doce trabajos impuestos por Euristeo a Hércules, pero en realidad decretados por Hera/Juno, la diosa enemiga del héroe. De este modo, Mrs. Herbert queda también identificada mitológicamente con la esposa de Zeus/Júpiter. El hecho de que los dibujos estén contratados no elimina el carácter último de imposición de la tarea, que finaliza con la muerte del dibujante, sibilinamen- te prevista desde el principio por la pareja femenina contratante. Algunos detalles, en apariencia nimios, refuerzan este paralelismo entre los dibujos y los trabajos. Por ejemplo, el rebaño que una mano negra deja suelto una mañana, y que Mr. Neville intenta dispersar a patadas, recuerda al episodio del ganado de Gerión y el de los establos de Augías, el encuentro sexual con Mrs. Talmann en una cuba llena de manzanas retoma aspectos del episodio de Hércules con Onfale, etcétera.

Por otra parte, al igual que Hércules es un semidiós, ni mortal ni plenamente inmortal, el dibujante pertenece a una clase social incierta. Es odiado por los aristócratas, que se sirven de él, al igual que Hércules es odiado por algunos dioses, que no obstante se aprovechan de sus cualidades. Este aspecto está reforzado por la época en la que transcurre el argumento. A finales del siglo XVII, tras el puritanismo de la época de Cromwell y el comienzo de la Restauración, en plena inestabilidad política, la consideración intelectual y social del artista en Inglaterra sufre importantes transformaciones. Tras la hegemonía de todo lo relacionado con lo italiano en cualquier terreno artístico, en la última década del siglo XVII la emergente burguesía inglesa empezará a confiar cada vez en mayor medida en los pintores de su propio país. Este cambio no impide sin embargo que lo que se espera de los artistas sea una prolongación del gusto italiano. Los dibujos que realiza Mr. Neville se inscriben en dicha tendencia italiana, a la que deben su carácter profundamente racionalista y supuestamente científico, ya que están basados en una rígida y escasamente imaginativa aplicación de los principios codificados por la tradición renacentista italiana. Dependen de un atril cuadriculado que funciona como diafragma y visor que permite trasladar la realidad al papel mediante las leyes de la perspectiva. Las medidas del visor se corresponden con la proporción $5 / 3$ 
$=1,6666$, presente en la serie de Fibonacci que origina la proporción áurea, número perfecto para toda estética clasicista basada en la armonía matemática. La sujeción del dibujante a estas leyes es tal, que cualquier mínima desviación o diferencia en la realidad le disgusta y turba profundamente, hasta el punto de ser incapaz de introducir en un primer momento cualquier alteración de lo real respecto al día anterior en su dibujo. Esta incapacidad imaginativa es criticada ácidamente por Mrs. Talmann, quien de este modo alude a la esterilidad creadora de Mr. Neville, pero en un sentido más profundo ataca la impotencia del arte (racional y masculino) frente a la fertilidad de la naturaleza y la mujer. De hecho, los dibujos son un subterfugio de las dos mujeres para lograr ser fértiles y tener descendencia.

Este fracaso simbólico de la razón frente la naturaleza es también el del moribundo siglo XVII, cartesiano, racionalista y mecanicista, frente al inminente siglo XVIII, ilustrado, deísta, naturalista y emocional, germen de su propia superación, el Romanticismo. Este conflicto se expresa a través del jardín. El pequeño jardín a la francesa que rodea la mansión, racionalista y geométrico, va a ser sustituido por otro dibujante e ingeniero que aparece en la película, Mr. Van Hoyten, quien va a transformar el jardín mediante un lago artificial, lo que adelanta el concepto inglés del jardín pintoresco que triunfará durante el siglo XVIII. El arte racionalista y perspéctico de Mr. Neville está condenado a fracasar, tanto personal como históricamente.

De este modo, el ataque de Mrs. Talmann a la falta de imaginación del dibujante se convierte en una triple humillación. Desde el punto de vista artístico, al rebajar su calidad como artista individual. Desde el punto de vista social, al reforzar la distancia existente entre la aristocracia, aunque sea rural y menor, y la imprecisa condición social del dibujante, un ambicioso que se atreve a pavonearse entre los aristócratas y burgueses, vistiendo siempre llamativas ropas distintas a las que ellos visten en cada momento. En tercer lugar, desde el punto de vista simbólico y mitológico, al proclamar la incapacidad creativa natural del hombre, que trata de suplir mediante la creación artística, frente a la fertilidad natural de la mujer.

Al igual que Hércules, el dibujante muere y alcanza una indeseada apoteosis, tras finalizar el duodécimo dibujo y antes de poder concluir el decimotercero. Este aspecto es más profundo de lo que parece. Al ser el doce el número solar por excelencia, el número de los meses, de los signos zodiacales y de las horas de cada parte del día, y el trece el número de los meses lunares, la transición del doce al trece es fatídi$\mathrm{ca}$, infausta y nefasta, como demuestran las abundantes supersticiones en torno a este número, cuya razón profunda última es de carácter astronómico. Al comenzar el decimotercer dibujo, Mr. Neville pasa del régimen solar y diurno al lunar y nocturno. Por ello el dibujo se empieza a realizar de noche. Pero en esta fatídica jornada número 13, los habitantes de la mansión asesinan al dibujante mediante una triple ordalía que conduce a una compleja muerte, acuática y ritual, que nos introduce en el tercer nivel mitológico de la película, el más profundo.

3) La Diosa Blanca y El rey sagrado. El ritualizado asesinato del dibujante consta de tres fases. Primero es cegado con fuego, después vapuleado, y por fin ahogado en un estanque. Pese a las alusiones a los mitos griegos presentes en toda la película, este nivel mitológico profundo enlaza también con la mitología céltica y cristiana sin dejar de pertenecer al mundo griego. Ello es posible porque la muerte del dibujante reproduce la muerte ritual del rey sagrado en el decimotercer mes lunar, tal como la describieron James Frazer en La Rama Dorada y 
Robert Graves en La Diosa Blanca4. Ambas obras sostienen la existencia de un estrato mitológico presente al menos hasta la llegada del cristianismo, cuyo mito fundamental es la vida y muerte del rey sagrado a manos de la diosa, la triple Diosa Blanca. Greenaway no ha citado nunca a Frazer o a Graves como inspiradores de su película, pero las coincidencias son tan numerosas y profundas que permiten considerarlas como una clave fundamental. El contenido del mito es sencillo. El rey sagrado disfruta de su reinado durante un año, al término del cual, en el decimotercer mes lunar, el rey se une sexualmente con mujeres que simbolizan a la diosa y a la naturaleza, y en las que engendrará descendencia. Tras esta cópula, el rey es sacrificado ritualmente y devorado por los miembros de la tribu. Según Frazer y Graves, en una segunda fase histórica, el rey elude su propio sacrificio mediante el de un niño y después el de un animal, el chivo expiatorio.

La muerte del dibujante reproduce este ritual y lo combina con otros ritos de sacrificio. En primer lugar, Mr. Neville es cegado con fuego. Como Mr. Herbert, el dueño asesinado de la mansión, teme y aborrece el fuego, puede ser identificado simbólicamente con Neptuno (de este modo, el dueño de la mansión condensa rasgos de Júpiter, Neptuno y Hades, los tres dioses fundamentales del panteón olímpico y dueños de la totalidad de los elementos). El agua está presente en la casa, en los estanques en el que aparece ahogado Mr. Herbert y en el que será arrojado el cuerpo del dibujante, y en la cuba llena de manzanas en la que Mr. Neville y Mrs. Talmann hacen el amor, entre otros elementos acuáticos. El agua, elemento femenino por excelencia, aparece asociada por tanto a la fertilidad y

-

${ }^{4}$ R. GRAVES, La Diosa Blanca, 2 vols., Alianza Editorial, Madrid, 1987. J. FRAZER, La rama dorada (selección), F.C.E., México, 1988. resulta ser fatídica para los hombres, en la que encuentran la muerte ${ }^{5}$. Que el dibujante sea cegado con fuego es una alusión irónica a las aspiraciones prometeicas de los artistas, castigadas por los dioses-aristócratas. Al ser apaleado, el dibujante sufre exactamente el mismo tormento que el rey sagrado, antes citado. Después del linchamiento, el dibujante aparece semidesnudo, envuelto por lienzos mojados y exhibiendo numerosas llagas, entre ellas en el costado y las manos. De este modo, se establece un paralelo profundo entre el artista y Cristo, no existente en la época, pero que tras el Romanticismo se convertirá en un tema de reflexión, por un lado en torno a la naturaleza divina del artista, y por otro como paralelo del propio Cristo, especialmente tras el De Profundis de Oscar Wilde. El círculo simbólico se cierra porque el propio Cristo es para Robert Graves el rey sagrado de los judíos, ungido como descendiente de David en una ceremonia secreta, como relata en su novela Rey Jesús ${ }^{6}$. Cegado y apaleado, el dibujante es arrojado al estanque bajo la estatua ecuestre del propietario. De este modo, ha sufrido una ordalía por el fuego, el agua y la tierra. El aire, que en la tradición hermética se corresponde con el intelecto, y que es por tanto la mente del protagonista, es castigado también mediante la quema de sus frutos, los dibujos.

En realidad, si el espectador se ha mantenido atento, recodará la voz que canta al comienzo de la película, resumiendo su sentido mítico más profundo: "La Reina de la Noche derrotó al Día”. La mujer vence y aplasta al hombre, la naturaleza al arte, la emoción a la razón. La clave última del sentido de la película reside en una música aparentemente incidental y secundaria.

\footnotetext{
${ }^{5}$ Un tema que retomará y ampliará Greenaway en Conspiración de mujeres (Drowning by numbers).

${ }^{6}$ Editorial Edhasa, Barcelona, 1984.
} 
4) Pan o the Greenmann. Un personaje desconcertante es el hombre-estatua. Por una parte, satiriza la costumbre de los aristócratas y burgueses de la época de comprar estatuas en el continente para adornar los jardines, lo cual realiza Mr. Herbert, por estupidez o esnobismo, con una estatua viviente $^{7}$. Pero existe un significado más profundo en este personaje. Jorge Gorostiza lo relaciona con el Greenman, el hombre salvaje o genio de los bosques de la tradición folklórica británica, emparentado con Pan, el dios griego de la naturaleza ${ }^{8}$. La estatua se confunde con la hiedra, orina, hace burla a un niño, y su última acción es morder y escupir un trozo de piña. El simbolismo de este acto es doble. Por un lado, la piña es un fruto exótico asociado en la Inglaterra de la época a la hospitalidad. Al escupirla, la estatua resume el destino del artista en la sociedad inglesa, admitido al principio, pero expulsado y rechazado en última instancia. Pero al mismo tiempo, el simbolismo de la piña como fruto asociado a la inmortalidad, permite leer la acción del Greenman como una señal de que el artista ha alcanzado una ácida y desagradable inmortalidad, sólo posible tras su muerte.

Otros detalles simbólicos refuerzan estas ideas. Como en todas las películas de Greenaway, los actos de contar, de deletrear la inicial de determinadas especies de la realidad, y de explicar sus propiedades, suponen una forma de intentar ordenar el caos y convertirlo en cosmos, un intento de antemano condenado al fracaso, a la derrota de la razón a manos de la naturaleza. En El Contrato del Dibujante se habla de numerosos árboles y frutos. Ciruelas, naranjas, manzanas, granadas, piñas y peras son las frutas de las que se comentan sus propiedades. La A de albaricoque, la P de piña y

\footnotetext{
${ }^{7}$ J. GorostiZA, op. cit. pp. 68-69.
}

${ }^{8}$ Véase la obra de R. BARTRA, El salvaje en el espejo, Destino, Barcelona, 1996., sobre todo págs. 101-132. de pera, la L de limón, son algunas de las letras que comienzan a ordenar el mundo como un jardín. Los 13 tejos que se nombran encierran un gran significado. Al ser el tejo el árbol de la muerte en la tradición céltica, como recoge Robert Graves en $\mathrm{La}$ Diosa Blanca, y el 13 el número lunar, mortuorio e infausto, los trece tejos adelantan simbólicamente que la muerte llegará con el número 13 , como efectivamente sucederá.

Toda esta serie de paralelismos permite resumir el sentido mitológico global de la película. En la mansión de un dios (Cronos/Zeus/Hades/Neptuno) temeroso del fuego, la Diosa, desdoblada en Deméter/Juno (Mrs. Herbert) y Perséfone (Mrs. Talmann), casada con un Hades estéril y ávido de posesiones (Mr. Talmann), encargan al rey sagrado del año, Hércules (Mr. Neville), doce dibujos diurnos, a cambio de favores sexuales que les permitan engendrar hijos. Una vez terminada la tarea, y tras un último y fatídico contrato para un decimotercer dibujo nocturno, el dibujante es sacrificado como rey sagrado del año. Pan certifica que ha alcanzado la inmortalidad. 